\title{
To run or to fly: low cost versus low risk escape strategies in blackbirds
}

\author{
Iñaki Rodriguez-Prieto ${ }^{1)}$, Esteban Fernández-Juricic ${ }^{2,3)}$ \\ \& José Martín ${ }^{1)}$ \\ ( ${ }^{1}$ Departamento de Ecología Evolutiva, Museo Nacional de Ciencias Naturales, CSIC, José \\ Gutiérrez Abascal 2, 28006 Madrid, Spain; ${ }^{2}$ Department of Biological Sciences, \\ California State University Long Beach (MS 3702), 1250 Bellflower Boulevard, \\ Long Beach, CA 90840, USA)
}

(Accepted: 3 March 2008)

\begin{abstract}
Summary
When escaping from predators, ground-foraging birds could choose between two escape strategies with different costs: running or flying. We simulated predator attacks on blackbirds Turdus merula to investigate the factors influencing blackbirds to select between these strategies. The probability that blackbirds would fly increased as flight initiation distance decreased, suggesting that they may trade-off benefits of delaying escape with a costly escape strategy. The probability of flying also increased as the number of potential predators increased, indicating an increase in perceived predation risk with the number of non-attacking predators. Running was more likely to be used in the mornings and flying in the afternoons, suggesting a possible mass-dependent predation risk effect or restrictions in the use of costly escape strategies when energetic reserves are lower. Juvenile blackbirds tended to fly away more often than adults, probably to compensate for their less reliable risk assessments due to lack of experience. We conclude that different factors act independently on choosing an optimal escape strategy, and that the decision about when to escape (flight initiation distance) is associated with the decision about how to escape (escape strategy), which in turn can affect the decision about how far to escape (distance fled).
\end{abstract}

Keywords: flight initiation distance, escape strategy, distance fled, landing distance.

\section{Introduction}

Numerous factors influence escape decisions in predator-prey encounters, with prey paying attention to factors related to predator size and behaviour,

3) Corresponding author's e-mail address: efernand@csulb.edu

(C) Koninklijke Brill NV, Leiden, 2008 
and to the social and physical environment (Stankowich \& Blumstein, 2005). When confronted with an approaching predator, prey use these factors to dynamically estimate the risk posed by the predator in every encounter (Bonenfant \& Kramer, 1996; Blumstein, 2003; Martín \& López, 2005; Cooper, 2006a). When the costs of staying in a spot (risk of being caught by the predator) equal the costs of leaving (flight energetic costs and lost foraging opportunities), prey should flee (Ydenberg \& Dill, 1986; Cooper \& Frederick, 2007). A recent model predicts the optimal flight initiation distance (FID) based on the initial expected fitness, benefits obtained during encounters, costs of escaping, and probability of being killed (Cooper \& Frederick, 2007). However, prey must not only decide when to escape, but also what escape strategy to use.

Many ground-foraging passerines can choose between two escape strategies: running or flying. When escaping by flying, prey greatly reduce predation risk by quickly increasing the predator-prey horizontal and/or vertical distance, but at the expense of high energetic costs associated with short and explosive flights (Butler, 1991; Nudds \& Bryant, 2000), and opportunity costs associated with leaving a profitable patch (Brown \& Kotler, 2004). On the other hand, when running, prey are exposed to higher predation risk than when flying because escape speed is lower and the distance between a bird and a predator is shorter at the end of the escape (Alonso, 2004). However, energetic costs associated with running are lower (Butler, 1991), and individuals would remain in the patch and hence can resume foraging quickly when the predator leaves. Running instead of flying also offers an opportunity for prey to continue gathering information about the risk posed by the predator through changes in its behaviour, thus avoiding the overestimation of risk.

The goal of this study was to assess how the use of two escape strategies (running vs. flying) is influenced by the factors that could affect the escape cost-and-benefit relationship: previous escape decision (flight initiation distance, FID), distance to cover, number of conspecifics and potential predators, time of the day, and age of the bird. We used the blackbird (Turdus merula) as the model prey species due to its abundance and previous knowledge on its escape behaviour (Fernández-Juricic \& Tellería, 2000; Fernández-Juricic et al., 2002; Blumstein et al., 2004). We used humans as model predators since human disturbance can cause anti-predator responses similar to those elicited by natural predators (Frid \& Dill, 2002). Previous studies have corroborated that blackbirds responded to humans as 
if they were potential predators (e.g., Fernández-Juricic \& Tellería, 2000; Fernández-Juricic et al., 2002; Blumstein et al., 2004).

We hypothesized that escaping by running away is advantageous when the probability of being captured while escaping is low. Other factors being equal, the farther the predator is from the prey when the prey starts to escape, the lower the probability of capturing the fleeing prey (Ydenberg \& Dill, 1986). Furthermore, predation risk increases with increasing distance to the nearest refuge (Fernández-Juricic et al., 2006), if cover is interpreted as protective (Lazarus \& Symonds, 1992). Therefore, we predicted that the probability of a bird escaping by running instead of flying would be higher as FID increases and the distance to the nearest refuge decreases.

When the number of nearby conspecifics increases, individual risk decreases. Thus, individuals may delay escape (e.g., Fernández-Juricic et al., 2002), but they may also lower the magnitude of their escape response by using a low-cost strategy. Thus, we predicted that increasing numbers of conspecifics would increase the chances of escaping by running. Predation risk increases with the number of predators (Beale \& Monaghan, 2004; Geist et al., 2005; Cooper et al., 2007); thus, we predicted that the probability of a bird flying away would be higher as the number of nearby potential predators increases.

Birds lose weight overnight and recover it during the day (Blem, 1990), yielding a pattern of lowest body mass in the early morning and highest at dusk (e.g., Macleod et al., 2005). Because higher mass could limit the ability of birds to evade predators (e.g., Bednekoff, 1996; Kullberg et al., 1996), the probability of using an escape strategy could also vary between morning and afternoon due to the increase in mass-dependent predation risk during the day (e.g., Bednekoff \& Houston, 1994; McNamara et al., 1994). We predicted that the low-cost but high-risk running strategy would be used more frequently in the mornings due to lower energetic reserves, whereas the low-risk but high-cost flying strategy would be preferred in the afternoon period when energetic reserves are higher.

Finally, we predicted that the selection of escape strategy would vary with the age of the bird. Some studies on mammals and birds have shown that juvenile animals have lower anti-predator experience and may make less reliable assessments of predation risk (Hanson \& Coss, 1997; Ramakrishnan $\&$ Coss, 2000; Rajala et al., 2003), which could led to a heightened risk of capture if they incorrectly use the running escape when actual predation risk 
is higher. Under these circumstances, it would pay to adopt a conservative strategy to decrease potential risk, even if escape costs increase. Therefore, we hypothesize that juvenile birds would benefit from systematically employing the safer escape (flying) upon deciding to flee, and hence they would fly away more often than adults.

\section{Methods}

The study was conducted in July and August 2004 in four wooded parks (Capricho, Moro, Oeste, Retiro) in the city of Madrid $\left(40.25^{\circ} \mathrm{N}, 03.43^{\circ} \mathrm{W}\right.$ ), Spain. These parks have lawns, native and exotic shrubs, and high tree cover with a mixture of coniferous and deciduous trees (see description of vegetation structure in Fernández-Juricic, 2000).

We gathered escape information during weekdays, between 0830 and 1130 (morning period) and between 1830 and 2130 (afternoon period), thus avoiding sampling during the hottest hours of the day. Madrid's summer daylight pattern provided similar visibility conditions in both time periods. We also avoided sampling during windy and rainy days.

We performed experimental approaches to blackbirds foraging on the ground, using a direct trajectory and a steady speed of $1 \mathrm{~m} / \mathrm{s}$, with no intervening vegetation blocking the view between the focal bird and the approaching observer. For each approached blackbird, we recorded its flight initiation distance (FID), defined as the distance between the approaching observer and the focal individual at which the latter flushed, the type of strategy used in the escape (running or flying), and the distance travelled while escaping (distance fled or landing distance, Fernández-Juricic et al., 2006). The observer stopped the approach as soon as the blackbird fled. Once the bird ended its escape, the observer walked to the bird initial position and then to the bird final position in order to measure FID and distance fled. None of the sampled individuals used a freezing or crouching response when responding to our approaches. The age of the focal bird (adult or juvenile) was determined using binoculars prior to the approach based on bill colour and plumage composition and colouration (Cramp, 1988). We discarded observations lacking accurate age identification. For each approach, we recorded the number of conspecifics within a $10-\mathrm{m}$ radius around the focal bird (Ikuta $\&$ Blumstein, 2003). In a 25-m radius circular plot centred on the focal bird, 
we also recorded for each approach: shrub cover $(\%)$, tree cover $(\%)$, mean shrub height $(\mathrm{m})$, mean tree height $(\mathrm{m})$ and number of pedestrians (potential predators) present at the start of the approach. Cover variables were estimated following the scales of Prodon \& Lebreton (1981). We also measured the distance from the focal bird's initial position to the nearest cover (shrub or tree). Vegetation structure (cover and height) and park identity were included in our statistical analyses as factors to control for their potential confounding effects. We did not include the sex of individuals as a variable in the analyses because there were no significant differences in escape strategy between adult males and females $\left(\chi_{1,147}^{2}=0.72, p=0.40\right)$, and we were unable to unequivocally identify juvenile sex.

We did not mark individual blackbirds but recorded their responses from randomly selected territories (following Fernández-Juricic \& Tellería, 2000). We are confident that this procedure allowed us to reduce the likelihood of sampling the same individual more than once, since blackbirds are highly territorial, expending most of their time within the boundaries of their nonoverlapping territories (Greenwood \& Harvey, 1978; Cramp, 1988).

We conducted a principal components analysis (PCA) to reduce the number of vegetation structure variables ( $\%$ tree cover, $\%$ shrub cover, mean tree height and mean shrub height). Following the Kaiser criterion (Kaiser, 1960), we selected only those PCA components with eigenvalues $>1$. Following the broken stick model for the PCA (Jackson, 1993) yielded similar results.

We ran a Generalized Linear Model to assess the effects of the different independent factors on blackbird escape strategies. We used a logit link function, with a binomially distributed response variable (running, flying). The model included categorical (age, park, and day period) and continuous factors (FID, number of conspecifics, number of pedestrians, PCA vegetation components, and distance to nearest cover). We did not include in the model the distance between the blackbird and the observer at the moment when the approach started (starting distance) despite its role in FID decisions (Blumstein, 2003), because it was highly correlated with FID $\left(F_{1,203}=84.10, p<0.001\right)$, and it was not associated with the escape strategy $\left(\chi_{1,203}^{2}=0.15, p=0.70\right)$. We present the mean probabilities $\pm \mathrm{SD}$ generated by the Generalized Linear Models (Statsoft, 2002).

To asses whether escape strategy could affect the distance that blackbirds moved after flushing, we also ran a General Linear Model to analyze the effects of different independent factors (escape strategy, age, day period, 


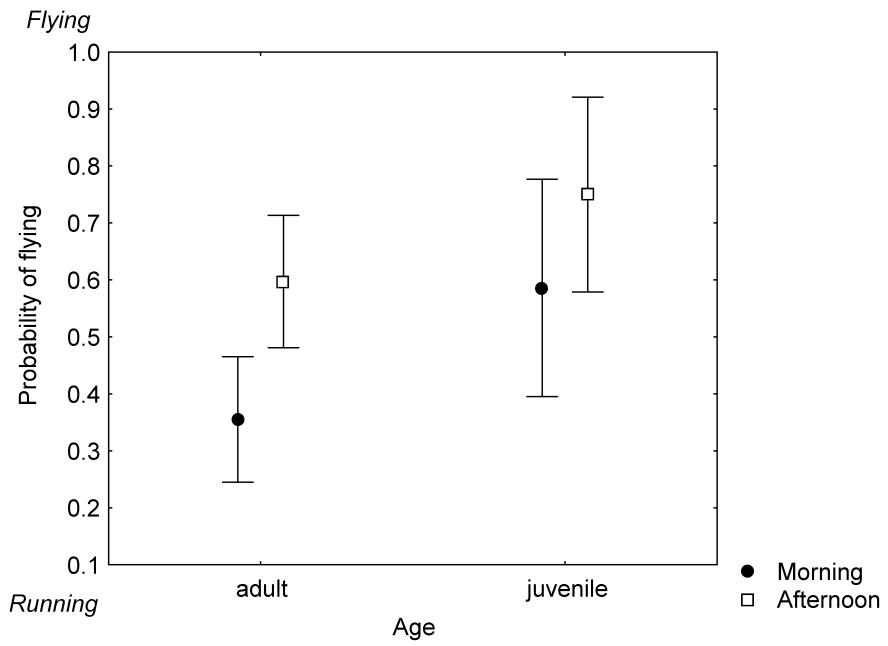

Figure 1. Mean probabilities of using a flying escape strategy for each age group (adults, juveniles), and for each day period (morning, afternoon). Lower flying probabilities indicate higher running probabilities. Means $\pm 1.96 \mathrm{SE}$ are shown based on a Generalized Linear Model with a binomial distribution and a logit function.

park, FID, number of conspecifics, number of pedestrians, distance to nearest cover and PCA vegetation factors) on distance fled.

We log-transformed all continuous variables to meet normality and homocedasticity assumptions. We present means $\pm \mathrm{SD}$ in the text and means $\pm \mathrm{SE}$ in Figure 1.

\section{Results}

Vegetation structure variables were reduced to two principal components (\% total variance explained; PC1, 32.53\%; PC2, 31.56\%). PC1 correlated positively with shrub height (factor loading $=0.81$ ) and tree height (factor loading $=0.70$ ); hence, representing a gradient of vegetation height. PC2 correlated positively with shrub cover (factor loading $=0.81$ ) and tree cover (factor loading $=0.76$ ), representing a gradient from areas with sparse to dense vegetation.

A total of 203 observations of escape sequences of blackbirds were used in the test, with 147 of them being adults ( 76 observed in the mornings and 72 in the afternoons) and 57 juveniles ( 29 observed in the mornings and 28 in the afternoons). The percentage of individuals that escaped by flying 
was: adults, $47.30 \%$; juveniles, $66.67 \%$. The proportion of blackbirds that flew away instead of running was $44.07 \%$ in the mornings and $60.16 \%$ in the afternoons. Flight initiation distance ranged from 1.5 to $95 \mathrm{~m}(16.70 \pm$ $13.13 \mathrm{~m})$. The number of pedestrians varied between 0 and $26(3.27 \pm 5.38)$, while the number of conspecifics varied between 0 and $4(0.49 \pm 0.71)$. The mean distance to the nearest cover was $3.17 \pm 1.85 \mathrm{~m}$, ranging from 0.75 to $12 \mathrm{~m}$.

Controlling for park and vegetation structure, escape strategy was significantly affected by FID, the number of pedestrians, age of the blackbird, and the period of the day (Table 1). However, we did not find significant interaction effects between these factors (Table 1). The probability of flying was significantly lower as FID increased (running, $16.12 \pm 11.27 \mathrm{~m}$; flying, $14.43 \pm 9.93 \mathrm{~m}$ ), and significantly higher as the number of people increased (running, $2.53 \pm 4.57$ pedestrians; flying, $3.81 \pm 5.91$ pedestrians) despite the small differences in FID and number of pedestrians between flying and running situations. The probability of flying was higher in juvenile than in adult birds, and higher in the afternoon than in the morning (Figure 1). There was a trend towards higher probability of flying as the distance to the nearest

Table 1. Effects of period of the day, age, park (and their interactions), FID, number of pedestrians, distance to cover and some confounding factors on blackbird escape type selection. $\chi^{2}$, Wald statistic.

\begin{tabular}{lccr}
\hline & $\chi^{2}$ & df & $p$ \\
\hline Intercept & 7.89 & 1,203 & $<\mathbf{0 . 0 1}$ \\
FID & 7.06 & 1,203 & $\mathbf{< 0 . 0 1}$ \\
Number of pedestrians $<25 \mathrm{~m}$ & 4.03 & 1,203 & $\mathbf{< 0 . 0 5}$ \\
Distance to cover & 1.99 & 1,203 & 0.16 \\
Number of conspecifics & 0.24 & 1,203 & 0.63 \\
Vegetation structure PC1 & 0.01 & 1,203 & 0.95 \\
Vegetation structure PC2 & 1.05 & 1,203 & 0.31 \\
Park & 3.67 & 3,203 & 0.30 \\
Period & 7.76 & 1,203 & $<\mathbf{0 . 0 1}$ \\
Age & 4.40 & 1,203 & $\mathbf{0 . 0 5}$ \\
Interaction Park $*$ Period & 2.33 & 3,203 & 0.51 \\
Interaction Park $*$ Age & 3.09 & 3,203 & 0.38 \\
Interaction Period $*$ Age & 0.35 & 1,203 & 0.55 \\
Interaction Park $*$ Period $*$ Age & 5.51 & 3,203 & 0.14 \\
\hline
\end{tabular}

Significant factors are shown in bold. 
Table 2. Effects of escape strategy, park, period of the day, age, FID, number of pedestrians, distance to cover and some confounding factors on distance fled.

\begin{tabular}{lccc}
\hline & $F$ & $\mathrm{df}$ & $p$ \\
\hline Intercept & 53.42 & 1,191 & $\mathbf{< 0 . 0 0 0 1}$ \\
FID & 0.57 & 1,191 & 0.45 \\
Number of pedestrians $<25 \mathrm{~m}$ & 0.10 & 1,191 & 0.75 \\
Distance to cover & 0.17 & 1,191 & 0.68 \\
Number of conspecifics & 1.75 & 1,191 & 0.19 \\
Vegetation structure PC1 & 0.04 & 1,191 & 0.83 \\
Vegetation structure PC2 & 0.01 & 1,191 & 0.97 \\
Park & 4.06 & 3,191 & $<\mathbf{0 . 0 1}$ \\
Period & 2.07 & 1,191 & 0.15 \\
Age & 1.81 & 1,191 & 0.18 \\
Escape strategy & 28.70 & 1,191 & $<\mathbf{0 . 0 0 0 1}$ \\
Interaction Escape strategy*Age & 0.01 & 1,191 & 0.92 \\
Interaction Escape strategy*Period & 0.52 & 1,191 & 0.47 \\
\hline
\end{tabular}

Significant factors are shown in bold.

refuge increased, but it was non-significant (Table 1). Similarly, the number of conspecifics did not affect the probability of using a given escape strategy (Table 1).

Controlling for the significant effects of park, escape strategy influenced the distance fled (Table 2), with blackbirds covering a shorter distance when running $(6.83 \pm 2.54 \mathrm{~m})$ than when flying $(12.05 \pm 7.66 \mathrm{~m})$. No other factor significantly influenced the distance fled (Table 2).

\section{Discussion}

Our results show that the type of escape strategy in ground-foraging blackbirds is associated with flight initiation distance, number of predators, age and period of the day. Furthermore, the type of escape strategy influences the distance fled.

Blackbirds that allowed closer predator approaches (e.g., lower FID) before fleeing escaped by flying more often than those that decided to flee at greater distances. Larger FID would reduce the risk of capture for a running bird, while shorter FID would require escaping by flying to reduce the 
higher risk of capture by a predator that is closer. The need to use energetically expensive flying when escape is delayed (short FID) might cause an increase in energetic costs when the escape begins nearer the predator (Cooper $\&$ Frederick, 2007). This would reduce the net benefits of delaying the escape, altering the balance of costs and benefits (Ydenberg \& Dill, 1986). Lind et al. (2003) found that the distance at which the attacking predator was detected influenced the flight behaviour of Parus major and Cyanistes caeruleus, with birds taking-off at greater angles when the attacker was detected at $1 \mathrm{~m}$ than at $2.3 \mathrm{~m}$. Similarly, some lizards use pursuit-deterrent signals when the predator is detected at great distance, but they escape without signalling if the predator is too close when detected (Dial, 1986; Hasson et al., 1989; Cooper, 2001). To our knowledge, ours is the first study showing that the prey decision about when to escape affects the escape strategy. However, we note that both decisions could be made simultaneously, and could be affecting each other.

In our study, a single observer walked towards the focal blackbird; however, a high number of pedestrians around the focal bird may have increased the perceived predation risk, likely because by escaping from the attacking predator the prey could move closer to other potential predators. This resulted in prey being moe likely to fly instead of running away when the number of pedestrians increased. Flying may enhance speed, manoeuvrability and the ability to pass over pedestrians. Previous studies have found an effect of the number of attacking predators on FID (Geist et al., 2005; Cooper et al., 2007). Our results suggest that the number of non-attacking predators in the area also influences prey escape decisions.

The probability of flying was higher in the afternoons than in the mornings. The four study areas differed in the temporal pattern of human visitation: whereas Retiro and Oeste had the highest numbers of human visitors per unit time in the afternoons, Capricho was most visited in the mornings, and Moro had constant numbers of visitors during the day (Rodriguez-Prieto et al., unpublished data). However, escape strategy was not influenced by the interaction between study area and period of the day (Table 1), suggesting that the average level of human disturbance was not responsible for the temporal variation in escape strategy.

Many birds exhibit a daily increase in predation risk from dawn to dusk due to daily mass gain (Bednekoff \& Houston, 1994; McNamara et al., 1994; 
Macleod et al., 2006). Blackbirds may use more expensive but safer strategies later in the day to reduce the higher risk associated with greater mass (Cresswell, 1998). Nonetheless, considering that seasonal mass variation far exceeds diurnal mass variation (Macleod et al., 2005), it could be argued that the relatively small diurnal mass gains of blackbirds in the summer (Macleod et al., 2005) would have little effect on predation risk in birds able to survive with much higher mass loads in winter (Cresswell, 1998; Macleod et al., 2005). Alternatively, the reduced energetic reserves of blackbirds in the morning, following the overnight fast, could lead to preferential use of running, a low-cost strategy, early in the day. Higher energy reserves in the afternoon could lead to the use of the costly but safer flying strategy later in the day. We speculate that within-day variation in escape strategies would be more pronounced in the winter than in the summer months, because blackbirds generally increase energetic consumption in the mornings during the non-breeding season (Macleod et al., 2005), which could favour the use of safer escape strategies in the afternoon when energetic reserves are mostly met.

Juvenile birds escaped by flying more often than adult birds. This result does not seem to stem from juvenile birds making frequent inappropriate escape decisions, because then we would expect two kinds of inappropriate decisions (i.e., running when the actual predation risk is high, and flying when predation risk is low). Instead, we found a trend of more frequent use of flying in juveniles than in adult birds. We speculate that juveniles adopt this strategy based on their vulnerability (Hanson \& Coss, 2001; Platzen \& Magrath, 2005): the consistent use of flying may be an adaptive response of juvenile blackbirds to the reduced reliability of their predation risk assessments, as found in other species (Hanson \& Coss, 1997; Ramakrishnan \& Coss, 2000; Rajala et al., 2003). By flying, juveniles avoid the danger of risky running escapes when the actual predation risk is high, which may increase survival, but at the expense of higher energetic expenditure due to superfluous flying escapes. The lack of a significant relationship between distance fled and age suggests that juvenile birds do not compensate their higher use of flying with a decrease in the mean distance fled; hence, we believe that they actually pay higher energetic costs and use safer escape strategies than adults.

Prey may favour escape strategies that allow longer periods of risk assessment in which new information on predator reactions to prey behaviour can 
be gathered (Hall et al., 1986; Domenici \& Blake, 1993; Cooper et al., 2007), which could optimize subsequent escape decisions. Running away but maintaining visual contact with the predator instead of flying would offer this extra opportunity for prey to assess the actual risk posed by the predator. Thus, reduced use of running by juveniles might also represent the limited ability of inexperienced birds to obtain cues about predator behaviour. An alternative explanation to the differences in escape strategies between adults and juveniles is that some adults moult their wing feathers in July/August while the juveniles do not (Cramp, 1988), which could lead to reduced flying ability in some adults.

Blackbirds may not rely on distance to cover to make escape decisions because, they did not use vegetation preferentially for cover after escape (65.1\% of blackbirds ended their escape in the open). The lack of effect of the number of surrounding conspecifics could be because of the narrow range in conspecific numbers (0-4) in this territorial species, which may not benefit from larger aggregations (Greenwood \& Harvey, 1978).

The significant relationship between escape strategy and distance fled highlights the sequential structure of escape decisions. Blackbirds expending energy on more costly escape strategies (e.g., flying) tended to flee longer distances. The lack of direct relationship between FID and distance fled contrasts with findings in other taxa like grasshoppers (Cooper, 2006b) and lizards (e.g., Martín \& López, 2003; Cooper \& Wilson, 2007). However, in blackbirds the relationship between these escape decision phases may be indirect through the effects of escape strategy.

Overall, this study shows that the blackbird decision about when to escape (FID) influences the optimal decision about how to escape (escape strategy), which in turn determines the decision about how far to escape (distance fled). Moreover, other factors (age, time of day, number of predators) also influence escape strategies.

\section{Acknowledgements}

We thank Arturo Rodríguez, Reyes Román, and especially Yohana Regis for help collecting data. Ayuntamiento de Madrid and Patrimonio Nacional granted the necessary permits for work in Madrid parks. El Ventorrillo Field Station provided logistical support. Dave Shutler, William C. Cooper and two anonymous referees provided useful comments to improve the draft. E.F.J. was supported by the College of Natural Sciences and Mathematics, California State University Long Beach. J.M. was supported by the MCYT project BOS 2002-00547. 


\section{References}

Alonso, C.L. (2004). El riego de depredación en passeriformes: factores determinantes y estrategias para minimizar su efecto. - PhD thesis, Universidad Complutense de Madrid, Madrid.

Beale, C.M. \& Monaghan, P. (2004). Human disturbance: people as predation-free predators? - J. Appl. Ecol. 41: 335-343.

Bednekoff, P.A. (1996). Translating mass dependent flight performance into predation risk. An extension of Metcalfe and Ure. — Proc. Roy. Soc. Lond. B: Biol. 263: 887-889.

Bednekoff, P.A. \& Houston, A.I. (1994). Dynamic models of mass-dependent predation, risksensitive foraging, and premigratory fattening in birds. - Ecology 75: 1131-1140.

Blem, C.R. (1990). Avian energy storage. - In: Current ornithology (Power, D.M., ed.). Plenum Press, New York, NY, p. 59-113.

Blumstein, D.T. (2003). Flight initiation distance in birds is dependent on intruder starting distance. - J. Wildl. Manage. 67: 852-857.

Blumstein, D.T., Fernández-Juricic, E., LeDee, O., Larsen, E., Rodriguez-Prieto, I. \& Zugmeyer, C. (2004). Avian risk assessment: effects of perching height and detectability. Ethology 110: 273-285.

Bonenfant, M. \& Kramer, D.L. (1996). The influence of distance to burrow on flight initiation distance in the woodchuck, Marmota monax. — Behav. Ecol. 7: 299-303.

Brown, J.S. \& Kotler, B.P. (2004). Hazardous duty pay and the foraging cost of predation. Ecol. Lett. 7: 999-1014.

Butler, P.J. (1991). Exercise in birds. — J. Exp. Biol. 160: 233-262.

Cooper, W.E. (2001). Multiple roles of tail display by the curly-tailed lizard Leiocephalus carinatus: pursuit deterrent and deflective roles of a social signal. - Ethology 107: 1137-1149.

Cooper, W.E. (2006a). Dynamic risk assessment: prey rapidly adjust flight initiation distance to changes in predator approach speed. - Ethology 112: 858-864.

Cooper, W.E. (2006b). Risk factors and escape strategy in the grasshopper Dissosteira carolina. - Behaviour 143: 1201-1218.

Cooper, W.E. \& Frederick, W.G. (2007). Optimal flight initiation distance. - J. Theor. Biol. 244: 59-67.

Cooper, W.E. \& Wilson, D.S. (2007). Beyond optimal escape theory: microhabitats as well as predation risk affect escape and refuge use by the phrynosomatid lizard Sceloporus virgatus. - Behaviour 144: 1235-1254.

Cooper, W.E., Pérez-Mellado, V. \& Hawlena, D. (2007). Number, speeds and approach path of predators affect escape behaviour by the Balearic lizard Podarcis lilfordi. - J. Herpetol. 41: 197-204.

Cramp, S. (1988). Handbook of the birds of Europe, the Middle East and North Africa. The birds of the Western Palearctic. Vol. 5. Tyrant flycatchers to trushes. - Oxford University Press, Oxford.

Cresswell, W. (1998). Diurnal and seasonal mass variation in blackbirds Turdus merula: consequences for mass-dependent predation-risk. - J. Anim. Ecol. 67: 78-90.

Dial, B.E. (1986). Tail display in two species of iguanid lizards: a test of the "predator signal" hypothesis. - Am. Nat. 127: 103-111.

Domenici, P. \& Blake, R.W. (1993). Escape trajectories in Angelfish (Pterophyllum eimekei). — J. Exp. Biol. 177: 253-272. 
Fernández-Juricic, E. (2000). Bird community composition patterns in urban parks of Madrid: the role of age, size and isolation. - Ecol. Res. 15: 373-383.

Fernández-Juricic, E. \& Tellería, J.L. (2000). Effects of human disturbance on spatial and temporal feeding patterns of Blackbird Turdus merula in urban parks in Madrid, Spain. — Bird Study 47: 13-21.

Fernández-Juricic, E., Jiménez, M.D. \& Lucas, E. (2002). Factors affecting intra- and interspecific variations in the difference between alert distances and flight distances for birds in forested habitats. - Can. J. Zool. 80: 1212-1220.

Fernández-Juricic, E., Blumstein, D.T., Abrica, G., Manriquez, L., Adams, L.B., Adams, R., Daneshrad, M. \& Rodriguez-Prieto, I. (2006). Relationships of anti-predator escape and post-escape responses with body mass and morphology: a comparative avian study. Evol. Ecol. Res. 8: 731-752.

Frid, A. \& Dill, L.M. (2002). Human-caused disturbance stimuli as a form of predation risk. - Conserv. Ecol. 6: 11.

Geist, C., Liao, J., Libby, S. \& Blumstein, D.T. (2005). Does intruder group size and orientation affect flight initiation distance in birds? - Anim. Biodivers. Conserv. 28: 69-73.

Greenwood, P.J. \& Harvey, P.H. (1978). Foraging and territory utilization of blackbirds (Turdus merula) and song trushes (Turdus philomelos). - Anim. Behav. 26: 1222-1236.

Hall, S.J., Wardle, C.S. \& Maclennan, D.N. (1986). Predation evasion in a fish school: test of a model for the fountain effect. - Mar. Biol. 93: 143-148.

Hanson, M.T. \& Coss, R.G. (1997). Age differences in the response of California ground squirrels (Spermophilus beecheyi) to avian and mammalian predators. - J. Comp. Psychol. 111: 174-184.

Hanson, M.T. \& Coss, R.G. (2001). Age differences in the response of California ground squirrels (Spermophilus beecheyi) to conspecifics alarm calls. - Ethology 107: 259275.

Hasson, O., Hibbard, R. \& Ceballos, G. (1989). The pursuit deterrent function of tail-wagging in the zebra-tailed lizard (Callisaurus draconoides). — Can. J. Zool. 67: 1203-1209.

Ikuta, L.A. \& Blumstein, D.T. (2003). Do fences protect birds from human disturbance? Biol. Conserv. 112: 447-452.

Jackson, D.A. (1993). Stopping rules in principal components analysis: a comparison of heuristical and statistical approaches. — Ecology 74: 2204-2214.

Kaiser, H.S. (1960). The application of electronic computers to factor analysis. - Educ. Psychol. Meas. 20: 141-151.

Kullberg, C., Franson, T. \& Jakobsson, S. (1996). Impaired predator evasion in fat blackcaps. — Proc. Roy. Soc. Lond. B: Biol. 263: 1671-1675.

Lazarus, J. \& Symonds, M. (1992). Contrasting effects of protective and obstructive cover on avian vigilance. - Anim. Behav. 43: 519-521.

Lind, J., Hollén, L., Smedberg, E., Svensson, U., Vallin, A. \& Jakobsson, S. (2003). Detection distance influences escape behaviour in two parids, Parus major and P. caeruleus. - J. Avian. Biol. 34: 233-236.

Macleod, R., Barnett, P., Clark, J.A. \& Cresswell, W. (2005). Body mass change strategies in blackbirds Turdus merula: the starvation-predation-risk trade-off. — J. Anim. Ecol. 74: 292-302.

Macleod, R., Barnett, P., Clark, J.A. \& Cresswell, W. (2006). Mass-dependent predation risk as a mechanism for house sparrow declines. - Biol. Lett. 2: 43-46. 
Martín, J. \& López, P. (2003). Changes in the escape responses of the lizard Acanthodactylus erythrurus under persistent predatory attacks. - Copeia: 408-413.

Martín, J. \& López, P. (2005). Wall lizards modulate refuge use through continous assessment of predation risk levels. - Ethology 111: 207-219.

McNamara, J.M., Houston, A.I. \& Lima, S.L. (1994). Foraging routines of small birds in winter: a theoretical investigation. - J. Avian. Biol. 25: 287-302.

Nudds, R.L. \& Bryant, D.M. (2000). The energetic costs of short flights in birds. - J. Exp. Biol. 203: 1561-1572.

Platzen, D. \& Magrath, R.D. (2005). Adaptive differences in response to two types of parental alarm call in altricial nestlings. — Proc. Roy. Soc. Lond. B: Biol. 272: 1101-1106.

Prodon, R. \& Lebreton, J.D. (1981). Breeding avifauna of a Mediterranean succession: the holm oak and the cork oak series in the eastern Pyrénées. 1: Analysis and modelling of the structure gradient. - Oikos 37: 21-38.

Rajala, M., Rätti, O. \& Suhonen, J. (2003). Age differences in the response of willow tits (Parus montanus) to conspecifics alarm calls. — Ethology 109: 501-509.

Ramakrishnan, U. \& Coss, R.G. (2000). Age differences in the responses to adult and juvenile alarm calls by Bonnet Macaques (Macaca radiata). — Ethology 106: 131-144.

Stankowich, T. \& Blumstein, D.T. (2005). Fear in animals: a meta-analysis and review of risk assessment. — Proc. Roy. Soc. Lond. B: Biol. 272: 1433-1442.

Statsoft (2002). Statistica, version 6. - Statsoft, Tulsa, OK.

Ydenberg, R.C. \& Dill, L.M. (1986). The economics of fleeing from predators. - Adv. Stud. Behav. 16: 229-249. 